\title{
THE EFFICACY OF INTERMITTENT PNEUMATIC COMPRESSION ASA SUBSTITUTE FOR MANUAL LYMPHATIC DRAINAGE IN COMPLETE DECONGESTIVE THERAPY IN THE TREATMIENT OF BREAST CANCER RELATED LYMPHEDEMA
}

\author{
C. Sanal-Toprak, T. Ozsoy-Unubol, Y. Bahar-Ozdemir, G. Akyuz
}

Marmara Üniversitesi Eğitim Araştırma Hastanesi Fiziksel Tıp ve Rehabilitasyon Anabilim Dalı Pendik/Istanbul, Turkey

\section{ABSTRACT}

The aim of this study is to evaluate the efficacy of intermittent pneumatic compression (IPC) as a substitute for manual lymphatic drainage (MLD) in complete decongestive therapy (CDT) for treatment of advanced stages of breast cancer-related lymphedema. In this randomized, single-blind, controlled study, 46 patients with breast cancer-related lymphedema were divided into 2 groups. Both MLD with compression bandage (CB) group $(n=24)$ and IPC with CB group $(n=22)$ received treatment 3 days a week for 5 weeks. Home exercise program was also given to all patients. At the end of the $5^{\text {th }}$ week, patients were treated with a daily 23-hour compression garment and home exercise routines. Assessments were taken at baseline, the fifth week, and the third month. Arm circumference was measured at 5 different areas, shoulder range of motion (ROM) was evaluated with a goniometer, pain, and tightness, and heaviness sensations were assessed with visual analog scale. Both groups had similar demographic and clinical characteristics $(p<$ 0.05). There were no significant differences between groups and both groups showed significant improvement $(p<0.05)$ in the five measurement levels of the arm circumference at the fifth week and third month. Similarly, shoulder ROM, pain, tightness, and heaviness sensations improved in both groups $(p<0.05)$. Both MLD and IPC as a component of CDT were found successful at 5 weeks and 3 months without superiority to each other.

Keywords: lymphedema, complete decongestive therapy, intermittent pneumatic pump, lymphedema treatment, manual lymphatic drainage

Lymphedema is a condition that is characterized by the localized or generalized accumulation of protein-rich fluid that results from congenital malformation or acquired lymphatic obstruction or disruption (1). In patients who have undergone breast cancer treatment, lymphedema occurs due to impaired lymphatic drainage of the upper extremity as a consequence of operation, axillary radiation, and/or axillary lymph node dissection. The incidence of lymphedema after breast cancer treatment varies according to diagnostic criteria for lymphedema and duration of follow-up periods. While one study determined incidence of lymphedema to be $41.1 \%$ within a ten-year follow-up period (2), another study revealed that 
its incidence ranged from $15 \%$ to $54 \%$ within a three-year follow-up period (3). In one meta-analysis, sentinel lymph node biopsies were reported to decrease risk of lymphedema four times more than axillary dissections (4). More aggressive and anatomically destructive treatments can cause post-operative complications such as seroma, hematoma, infection, and axillary band (axillary web syndrome), and increase the risk of lymphedema (5). Lymphedema is primarily diagnosed through evaluation of clinical criteria. In addition to swelling of the affected extremities, certain symptoms, such as pain, fatigue, tightness, heaviness, tingling, weakness, and movement restriction, can also be seen in lymphedema $(6,7)$. Moreover, cellulitis, acanthosis, skin necrosis, elephantiasis, hyperkeratosis, and lymphangiosarcoma can accompany these findings (8). The appearance of anatomical structures such as veins, tendons, skin folds, and bony landmarks, frequently disappear (1). In general, shoulder pain and restriction of its motion following breast cancer treatment occur at a rate of $9-68 \%$ and $1-67 \%$, respectively (9). It has been reported that $16 \%$ to $43 \%$ of patients with breast cancer have shoulder dysfunction in the following year after surgery (3). Lymphedema is mostly evaluated through arm circumference measurements, water displacement measurements, tonometry, bioimpedance analysis, ultrasonography (US), computed tomography (CT), lymphoscintigraphy, and magnetic resonance imaging (MRI) (10). Circumference measurements are made at equidistant points from specific anatomical points, such as bony landmarks (olecranon, ulnar styloid, or metacarpophalangeal joints) or antecubital fossa (11). Studies have used various criteria and methodologies to measure arm circumference. While a difference in circumference of at least $2 \mathrm{~cm}$ at any of the 4 measured points between two arms is considered to indicate lymphedema, circumference differences of $2 \mathrm{~cm}$ or more in at least 3 points that are measured from 6 or 7 points are also occasionally accepted to indicate lymphedema (12). According to the lymphedema staging, there are four stages ( 0 to 3 ) gradually increasing from clinically normal to fibrotic irreversible tissue $(13,14)$.

Targets in treatment of lymphedema include controlling symptoms and preventing complications (15). In early stages, protective measures and detailed information should be given to patients to increase their awareness after breast cancer surgery. Active range of motion exercises should also be recommended to provide patients' extremity mobility. In 1988, the American Cancer Society emphasized the need for priority to diagnostic and treatment strategies and recommended use of various physical therapy modalities and rehabilitation methods to control symptoms and reduce complications $(1,16)$. For treatment of lymphedema, a multimodal technique called complete decongestive therapy (CDT) can be used to reduce the lymphedema and maintain skin and supporting structures' health (17). CDT consists of two-phase treatment program. The first phase (treatment phase) includes nail and skin care, therapeutic exercises, manual lymphatic drainage (MLD) and limb compression with bandaging. The second phase (maintenance phase) aims for conservation of the results gained from phase 1. It consists of compression garments, skin care, and continued exercises (17). MLD is frequently used in the form of rhythmic skin compression, which is achieved through the application of pressure with the hands or fingers (approximately $30 \mathrm{mmHg}$ ), to soften fibrotic induration, increase lymphatic transport, and remove increased interstitial fluid (18). MLD begins with the compressive stimulation of nearby drainage areas (e.g., neck, counter-axilla, etc.) and then continues with the successive manual decongestion of the affected chest wall, shoulder, arm, forearm, wrist, and hand. Intermittent pneumatic compression (IPC) is another treatment modality for the lymphedema. This technique uses pneumatic pumps to relieve the formation of edema and to remove fluid that has accumulated in the limbs with external compression. Pneumatic pumps apply single or multiple compartments around the affected extremity and these devic- 
es function through the application of fixed or intermittent pressure for a certain period of time. In addition, compression bandages (CB) can be used to provide increased lymphatic flow, increase the pumping of muscles, and reduce interstitial fluid formation (15). Finally, compression garments are applied to increase venous return and lymphatic flow and reduce accumulation of proteinaceous substances. Compression garments can also provide volume control, skin integrity, proper shaping of extremities, and protect the extremities from potential trauma (5).

Some studies have evaluated the effectiveness of IPC, but a conclusion is still unclear due to conflicting results and these studies did not establish optimal application parameters (19-21). MLD requires a well trained specialized therapist who sometimes is not easily available in hospitals or treatment centers worldwide. Therefore, we aimed to investigate the efficacy of IPC as an alternative to MLD in CDT.

\section{MATERIALS AND METHODS}

The study was approved by the local ethics committee of Marmara University. This randomized, single-blind study included patients with stage 2-3 lymphedema who had agreed to participate in the study. They were between 18-70 years old and were at least 3 months past breast surgery. Those with signs of cellulitis, lymphangitis, fungal infection, metastases to the lymph nodes, and uncontrolled psychiatric or systemic diseases were excluded from the study. For diagnosis of lymphedema, detailed physical examinations and arm circumference measurements were performed on patients who had been referred to an oncologic rehabilitation clinic. Patients were randomized into two groups. Patients in group $1(\mathrm{IPC}+\mathrm{CB})$ were treated with IPC (30 min), compressive bandages, and home exercise program. Patients in group 2 (MLD+CB) were treated with MLD (30 min), compressive bandages, and home exercise program. A total of 15 sessions ( 5 weeks) of IPC or MLD were applied to both groups 3 times per week, and after each session, the compressive bandaging was repeated. Ladder, pendulum, and range of motion exercises were given for affected upper extremities and organized for the home exercise programs. At the end of the 5th week, patients in both groups were treated with a daily 23-hour compression garment and home exercise routines. Patients were evaluated for circumference differences between the 2 arms with a nonelastic tape measure at five levels: metacarpophalangeal joints, wrist, $15 \mathrm{~cm}$ distally from the medial epicondyle, medial epicondyle, and $15 \mathrm{~cm}$ proximally from the medial epicondyle (22-24). Shoulder pain and sensations of tightness and heaviness were also evaluated with a $100 \mathrm{~mm}$ horizontal visual analogue scale (VAS) ranging from " $0 \mathrm{~mm}$ " (no discomfort) to "100-mm" (worst imaginable). Goniometric measurements of shoulder range of motion (ROM) were completed. All assessments were completed at baseline, the fifth week, and the third month by a researcher who blinded to treatment methods. Manual lymphatic drainage was performed by an expert massage therapist. During application, a pressure of approximately $30-45 \mathrm{mmHg}$ was applied with the hands and fingers. A 12-chamber sequential gradient compression pump was used for the IPC treatment. Inflation pressures ranged from 50 to $80 \mathrm{mmHg}$, and the garment was inflated fully from distal to proximal. Inflation time lasted for $\mathbf{6 0}$ seconds. Once the entire garment reached full inflation, it was deflated and the cycle repeated. Deflation time lasted for 25 seconds. Full treatment was 30-minutes in duration.

Findings of this study were evaluated through statistical analysis using the SPSS 22.0 statistical package program. In addition to descriptive statistical methods (mean, frequency, percentage and standard deviation), the Kolmogorov-Smirnov distribution test was used for examination of normal distribution parameters. Pearson's Chi-square test and Fisher's exact test were used for comparison of the qualitative data. The Mann-Whitney $\mathrm{U}$ test was used for comparison of the inter- 
group parameters. Friedman test was used for repeated comparisons and Wilcoxon signedrank test was performed with a Bonferroni correction for pairwise comparisons. Results were evaluated at a $95 \%$ confidence interval and a significance level of $p<0.05$.

\section{RESULTS}

The study was conducted between March 2014 and March 2015 with a total of 46 patients. The mean (SD) ages of the patients were $55.36(10.30)$ years and $59.04(2.83)$ years in the $\mathrm{IPC}+\mathrm{CB}$ and MLD+CB groups, respectively. Demographic and clinical characteristics of both groups were similar $(\mathrm{p}>0.05)$ (Table 1).

Only one significant difference in the groups was identified. Modified radical mastectomy rates were significantly higher in the IPC+CB group than they were in the MLD+CB group $(\mathrm{p}<0.05)$ (Table 2).

There were no significant differences between the groups with both treatment modalities (MLD+CB and IPC $+\mathrm{CB}$ ) resulting in significant decreases from baseline $(p$

\begin{tabular}{|c|c|c|c|}
\hline \multicolumn{4}{|c|}{$\begin{array}{l}\text { TABLE } 1 \\
\text { Demographic and Clinical Characteristics of the IPC } \\
\text { with CB and MLD with CB Groups }\end{array}$} \\
\hline $\begin{array}{l}\text { Height mean (SD) (meters) } \\
\text { Weight mean (SD) (kilograms) } \\
\text { BMI mean (SD) }\left(\mathrm{kg} / \mathrm{m}^{2}\right)\end{array}$ & $\begin{array}{l}1.57(0.05) \\
74.55(14.73) \\
30.23(6.21)\end{array}$ & $\begin{array}{l}1.58(0.06) \\
77(11.18) \\
30.90(4.96)\end{array}$ & $\begin{array}{l}10.514 \\
10.321 \\
10.391\end{array}$ \\
\hline $\begin{array}{l}\text { Lymphedema duration } \\
\text { mean (SD) (median) (months) }\end{array}$ & $32.55(37.05)(12)$ & $49.38(47.45)(36)$ & ${ }^{2} 0.122$ \\
\hline $\begin{array}{r}\text { Lymphedema side n (\%) } \\
\text { Right } \\
\text { Left } \\
\end{array}$ & $\begin{array}{l}12(54.5 \%) \\
10(45.5 \%)\end{array}$ & $\begin{array}{l}13(54.2 \%) \\
11(45.8 \%)\end{array}$ & ${ }^{3} 0.979$ \\
\hline $\begin{array}{c}\text { Lymphedema stage } \mathrm{n}(\%) \\
2 \\
3\end{array}$ & $\begin{array}{l}19(86.4 \%) \\
3(13.6 \%)\end{array}$ & $\begin{array}{l}15(62.5 \%) \\
9(37.5 \%)\end{array}$ & ${ }^{3} 0.066$ \\
\hline
\end{tabular}

${ }^{1}$ Student $\mathrm{t}$ Test; ${ }^{2}$ Mann-Whitney U Test; ${ }^{3}$ Fisher's Exact Test

\begin{tabular}{|c|c|c|c|c|c|c|}
\hline \multicolumn{7}{|c|}{$\begin{array}{l}\text { TABLE } 2 \\
\text { Characteristics of Treatment Procedures in the IPC with CB and MLD with CB Groups }\end{array}$} \\
\hline & & $\underset{(n=22)}{\operatorname{IPC}}$ & $\%$ & $\begin{array}{l}\text { MLD } \\
(n=24)\end{array}$ & $\%$ & $\mathbf{p}$ \\
\hline \multirow{2}{*}{ Radiotherapy } & No & 2 & $9.1 \%$ & 0 & $0.0 \%$ & \multirow{2}{*}{0.223} \\
\hline & Yes & 20 & $90.9 \%$ & 24 & $100 \%$ & \\
\hline \multirow{2}{*}{ Chemotherapy } & No & 3 & $13.6 \%$ & 2 & $8.3 \%$ & \multirow{2}{*}{0.457} \\
\hline & Yes & 19 & $86.4 \%$ & 22 & $91.7 \%$ & \\
\hline \multirow{2}{*}{ Surgery method } & Modified radical & 19 & $86.4 \%$ & 14 & $58.3 \%$ & \multirow[b]{2}{*}{0.035} \\
\hline & $\begin{array}{l}\text { Breast-conserving } \\
\text { surgery }\end{array}$ & 3 & $13.6 \%$ & 10 & $41.7 \%$ & \\
\hline $\begin{array}{l}\text { Axillary lymph node } \\
\text { dissection }\end{array}$ & Yes & 22 & $100 \%$ & 24 & $100 \%$ & - \\
\hline
\end{tabular}

Fisher's Exact Test 
$<0.05$ ) in the five measurement levels of the arm circumference at the fifth week and the third month. In both groups, differences in the five measurement levels of the 2-arm circumference were higher in the third month than in the fifth week. However, this difference was statistically significant only in MLD+CB group at the level of medial epicondyle and $15 \mathrm{~cm}$ proximally from the medial epicondyle. The data in Table 3 shows arm circumference differences for both groups.
While there were significant improvements from the baseline in VAS scores of pain and the sensations of tightness and heaviness at the fifth week and third month $(\mathrm{p}<0.05)$, there were no significant differences between the scores for either group. In both groups, all VAS scores significantly increased in the third month compared to the fifth week. (Figs. 1-3).

In both groups, shoulder abduction and flexion ROM values significantly improved from the baseline at the fifth week and third month (Table 4).

\begin{tabular}{|c|c|c|c|c|c|}
\hline \multicolumn{6}{|c|}{$\begin{array}{l}\text { TABLE } 3 \\
\text { Baseline and Post-Treatment Difference in Measurements of IPC with CB and } \\
\text { MLD with CB Groups }\end{array}$} \\
\hline $\begin{array}{l}\text { Difference in } \\
\text { measurements } \\
\text { (cm) }\end{array}$ & МCP & Wrist & $\begin{array}{l}\text { 15-cm distally } \\
\text { from } M E\end{array}$ & ME & $\begin{array}{l}\text { 15-cm } \\
\text { proximally } \\
\text { from ME }\end{array}$ \\
\hline \multicolumn{6}{|c|}{ IPC group $(n=22)$} \\
\hline Baseline & $1(0.86-1.73)$ & $1.75(1.30-2.51)$ & $3.5(3.36-5.40)$ & $3(2.51-4.80)$ & $2.5(1.59-2.30)$ \\
\hline 5th Week & $0(0.15-1.027)$ & $0.75(0.64-1.77)$ & $2(1.90-3.74)$ & $2(1.34-3.15)$ & $1.25(0.91-2.81)$ \\
\hline 3rd Month & $0.5(0.23-1.04)$ & $1(0.82-1.90)$ & $2(1.95-4.00)$ & $2(1.69-3.76)$ & $1(1.17-2.37)$ \\
\hline $\mathrm{P}^{*}$ & 0.0001 & 0.001 & 0.0001 & 0.0001 & 0.0001 \\
\hline $\begin{array}{l}\text { Baseline / 5th } \\
\text { Week }\left(\mathrm{p}^{* *}\right)\end{array}$ & 0.0003 & 0.024 & 0.0003 & 0.0003 & 0.009 \\
\hline $\begin{array}{l}\text { Baseline / 3rd } \\
\text { Month }\left(\mathrm{p}^{* * *}\right)\end{array}$ & 0.003 & 0.036 & 0.0003 & 0.003 & 0.024 \\
\hline $\begin{array}{l}\text { 5th Week / 3rd } \\
\text { Month }\left(\mathrm{p}^{* *}\right)\end{array}$ & 1.371 & 0.687 & 1.497 & 0.102 & 1.308 \\
\hline \multicolumn{6}{|c|}{ MLD group $(n=24)$} \\
\hline Baseline & $1(0.77-1.65)$ & $2(1.34-2.58)$ & $4.75(3.77-5.94)$ & $4(3.28-5.10)$ & $3(2.40-4.06)$ \\
\hline 5th Week & $0(0.16-0.72)$ & $1(0.87-1.79)$ & $3.25(2.79-4.50)$ & $3(2.26-3.78)$ & $1.5(1.29-2.62)$ \\
\hline 3rd Month & $0(0.16-0.92)$ & $1(1.02-2.10)$ & $3.75(3.15-4.80)$ & $3.5(2.77-4.32)$ & $2(1.64-3.11)$ \\
\hline $\mathrm{P}^{*}$ & 0.0001 & 0.0001 & 0.0001 & 0.0001 & 0.0001 \\
\hline $\begin{array}{l}\text { Baseline / 5th } \\
\text { Week }\left(\mathrm{p}^{* *}\right)\end{array}$ & 0.0003 & 0.003 & 0.0003 & 0.0003 & 0.0003 \\
\hline $\begin{array}{l}\text { Baseline / 3rd } \\
\text { Month }\left(\mathrm{p}^{* *}\right)\end{array}$ & 0.015 & 0.042 & 0.009 & 0.042 & 0.006 \\
\hline $\begin{array}{l}\text { 5th Week / 3rd } \\
\text { Month }\left(\mathrm{p}^{* *}\right)\end{array}$ & 1.185 & 0.096 & 0.09 & 0.033 & 0.036 \\
\hline
\end{tabular}

*Friedman's test; ** Wilcoxon signed rank test and Bonferroni correction

Median (95\% Confidence Interval), IPC: Intermittent Pneumatic Compression, MLD: Manual lymphatic Drainage, MCP: Metacarpophalangeal, ME: Medial Epicondyle 

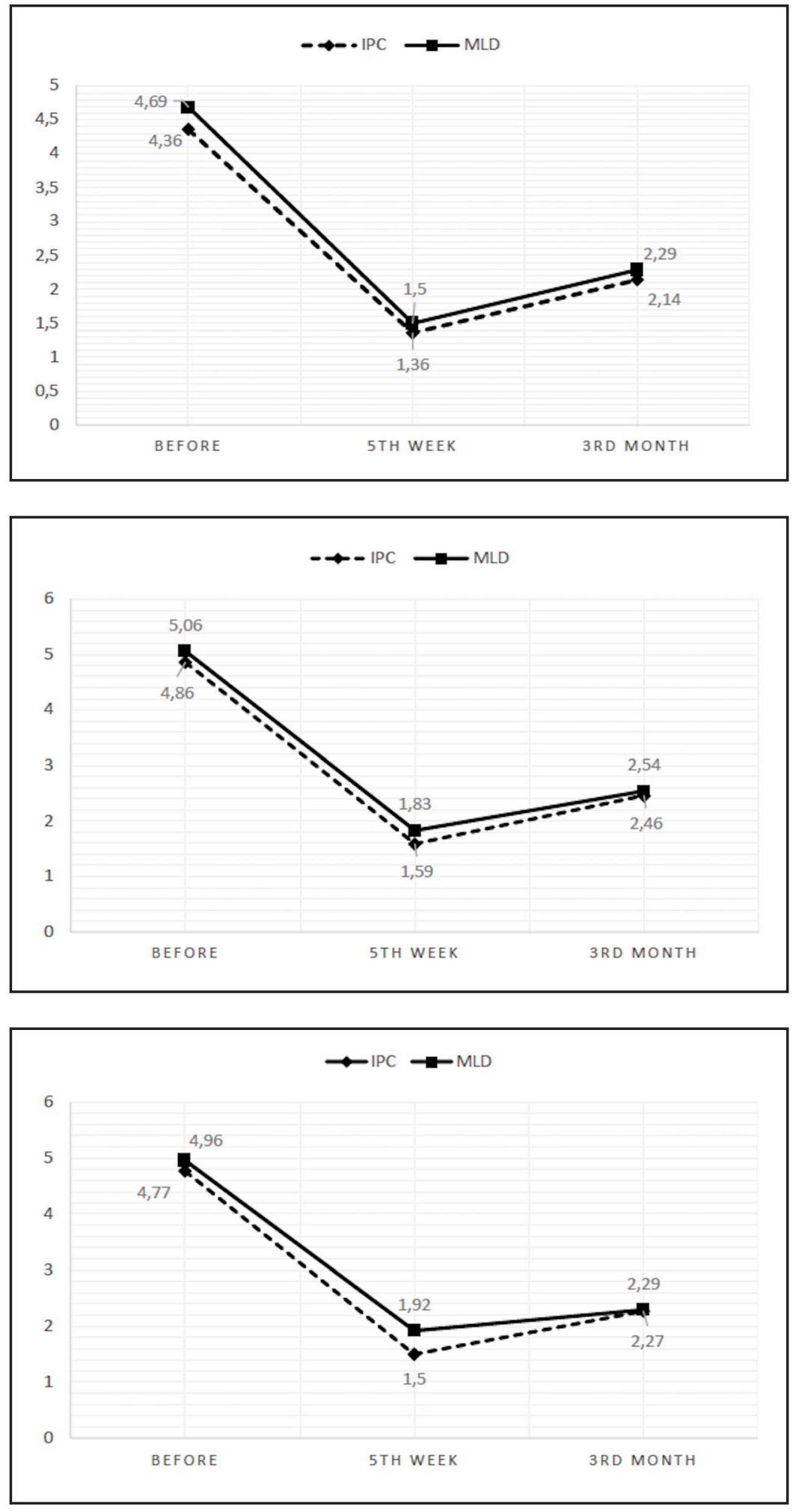

Fig. 1. Change of pain (VAS) scores over time for IPC with $C B$ and $M L D$ with CB groups.

Fig. 2. Change of tightness (VAS) scores over time for IPC with $C B$ and $M L D$ with $C B$ groups.

Fig. 3. Change of heaviness (VAS) scores over time for IPC with $C B$ and MLD with CB groups. 
TABLE 4

Changes in Shoulder Range-of-Motion (ROM) for IPC with CB and MLD with CB Groups

\begin{tabular}{|c|c|c|c|c|c|c|}
\hline $\begin{array}{l}\text { Shoulder } \\
\text { ROM } \\
(\text { mean } \pm \text { SD) }\end{array}$ & Abduction & Adduction & Flexion & Extension & $\begin{array}{l}\text { Internal } \\
\text { Rotation }\end{array}$ & $\begin{array}{l}\text { External } \\
\text { Rotation }\end{array}$ \\
\hline \multicolumn{7}{|c|}{ IPC group $(n=22)$} \\
\hline Baseline & $155.45 \pm 20.63$ & $38.86 \pm 5.96$ & $153.18 \pm 22.54$ & $37.27 \pm 4.55$ & $67.95 \pm 5.03$ & $75.68 \pm 12.37$ \\
\hline 5th Week & $166.36 \pm 12.16$ & $40.68 \pm 4.16$ & $166.36 \pm 12.55$ & $38.63 \pm 3.51$ & $69.54 \pm 2.13$ & $81.81 \pm 9.58$ \\
\hline 3rd Month & $165.90 \pm 12.6$ & $39.31 \pm 7.16$ & $165.90 \pm 13.33$ & $38.63 \pm 3.51$ & $69.54 \pm 2.13$ & $80.90 \pm 9.71$ \\
\hline $\begin{array}{l}\text { Baseline / } \\
\text { 5th Week } \\
\left(\mathrm{p}^{*}\right)\end{array}$ & 0.005 & 0.046 & 0.001 & 0.83 & 0.59 & 0.011 \\
\hline $\begin{array}{l}\text { Baseline / } \\
\text { 3rd Month } \\
\left(\mathrm{p}^{*}\right)\end{array}$ & 0.004 & 0.705 & 0.001 & 0.83 & 0.59 & 0.017 \\
\hline $\begin{array}{l}\text { 5th Week / } \\
\text { 3rd Month } \\
\left(\mathrm{p}^{*}\right)\end{array}$ & 0.317 & 0.180 & 0.317 & 1.00 & 1.00 & 0.317 \\
\hline \multicolumn{7}{|c|}{ MLD group $(n=24)$} \\
\hline Baseline & $152.08 \pm 23.02$ & $35.20 \pm 7.72$ & $151.66 \pm 20.78$ & $31.25 \pm 10.34$ & $63.54 \pm 9.83$ & $73.54 \pm 16.97$ \\
\hline 5th Week & $163.75 \pm 17.89$ & $38.12 \pm 7.04$ & $163.33 \pm 18.33$ & $35.83 \pm 8.29$ & $66.25 \pm 8.24$ & $76.25 \pm 15.26$ \\
\hline 3rd Month & $162.91 \pm 18.52$ & $37.5 \pm 7.07$ & $162.50 \pm 18.93$ & $35.41 \pm 8.33$ & $66.25 \pm 8.24$ & $75.83 \pm 15.29$ \\
\hline $\begin{array}{l}\text { Baseline / } \\
\text { 5th Week } \\
\left(\mathrm{p}^{*}\right)\end{array}$ & 0.001 & 0.027 & 0.0001 & 0.005 & 0.041 & 0.165 \\
\hline $\begin{array}{l}\text { Baseline / } \\
\text { 3rd Month } \\
\left(\mathrm{p}^{*}\right)\end{array}$ & 0.001 & 0.026 & 0.0001 & 0.004 & 0.041 & 0.379 \\
\hline $\begin{array}{l}\text { 5th Week I } \\
\text { 3rd Month } \\
\left(\mathrm{p}^{*}\right)\end{array}$ & 0.157 & 0.257 & 0.157 & 0.317 & 1.00 & 0.892 \\
\hline
\end{tabular}

*Wilcoxon signed rank test IPC: Intermittent Pneumatic Compression, MLD: Manual Lymphatic Drainage

\section{DISCUSSION}

This study aimed to compare the effectiveness of MLD and IPC methods as a component of CDT for the treatment of breast cancer-related lymphedema. Although MLD in CDT has been reported to be a successful method for the treatment of lymphedema, its accessibility is limited by a small number of specially trained therapists $(18,25-27)$.

Therefore, alternative methods such as IPC are more commonly used for the treatment of lymphedema. While the clinical application of this method is easier than MLD, its effectiveness is unclear due to conflicting results from studies and a lack of established optimal application parameters. IPC devices can be broadly categorized as follows: single-chamber, 
multi-chamber segmented without manual control, multi-chamber segmented - calibrated and advanced compression systems (28). We used a multi-chamber segmented-calibrated device with the aim to demonstrate its effectiveness in comparison with MLD in CDT. To the best of our knowledge, there is an insufficient number of studies that have compared MLD and IPC treatment methodologies. Results of these studies indicated no significant differences between MLD and IPC in CDT with each method proven to reduce lymphedema (19-21). The results of these studies are compatible with our results, but they assessed short-term effects of the treatment modalities. The current study is noteworthy because it tested a greater number of subjects than any existing study and more importantly, 3 month outcomes of both treatment methods were evaluated individually and compared with one another. Results revealed that compared to baseline, both methods had good outcomes for treatment of lymphedema in the $5^{\text {th }}$ week and $3^{\text {rd }}$ month. In addition, neither method was superior over the other. However, upon separate evaluations of results, while no significant differences for circumference measurements were determined in the IPC $+\mathrm{CB}$ group, the measurements were found to have significantly increased in the MLD+ CB group at the third month of testing compared to the fifth week. Therefore, the IPC+CB treatment may be considered superior in this particular respect. As recommended in existing literature, this study has also combined both treatments with bandaging and compression garment (10). The compression garments were recommended to the patients after the fifth week of both treatments, but we could not be sure of the patients' compliance with these applications completely. We suggest that potential noncompliance of patients in the MLD+CB group may have contributed to the significant increases to their arm circumference measurements at the third month of treatment. However, this is just a hypothesis and it needs further studies to evaluate compliance to compression garments including in the long-term follow-up period.
Also, other methods such as ultrasound or bioimpedence could be added as an assessment tool to investigate the importance of this difference.

This study has some limitations that should be considered in future research. First, this study lacks a control group of compression bandaging, exercise, and then compression garment without MLD or IPC. However, we could not include this due to the ethical concerns. Since the patients included in the study had advanced stages of lymphedema, they needed an efficient treatment strategy to provide increment in lymphatic flow. We thought that these patients could not wait without efficient treatment. Second, we did not evaluate patient satisfaction levels, which may have proven helpful in determining superiority of MLD or IPC treatment methods. However, the participation of all patients in every treatment session without dropouts lead us to believe that patient satisfaction was high. Third, we did not use any other measurement to confirm the arm circumference method. The use of water displacement, together with measurement of arm circumference, may have increased the strength of the study. Nevertheless, water displacement method is a time-consuming and unportable method for routine clinical use and arm circumference measurement is one of the most commonly used methods for lymphedema (29). Deltombe et al determined that intra-rater reliability was better than inter-rater reliability for measurements of arm circumference. This study also asserted that the same person should perform serial measurements on the same patients (30). Our study was therefore strengthened by the fact that all measurements were conducted by the same blinded researcher. In addition, pain and sensations of heaviness and tightness, which are the most common symptoms of lymphedema, were evaluated with VAS, and significant improvements were reported in both groups.

Both MLD+CB and IPC + CB methods were found to be effective treatment modalities with each producing significant reductions in symptoms of lymphedema. In conclusion, 
our results suggest that a multi-chamber segmented-calibrated IPC treatment can be substituted for MLD in CDT due to its easier accessibility and simple use in the outpatient clinic. This is especially important in areas of the world such as ours where it is difficult to acquire trained MLD therapists. Further studies with larger number of subjects and longer follow-up are needed to confirm our findings.

\section{CONFLICT OF INTEREST AND DISCLOSURE}

The authors declare no competing financial interests exist.

\section{REFERENCES}

1. Kozanoglu, E, S Basaran, S Paydas, et al: Efficacy of pneumatic compression and low-level laser therapy in the treatment of postmastectomy lymphoedema: A randomized controlled trial. Clin. Rehab. 23 (2009), 117-124.

2. Pereira, ACPR, RJ Koifman, A Bergmann: Incidence and risk factors of lymphedema after breast cancer treatment: 10 years of follow-up. Breast 36 (2017), 67-73.

3. Simşir Atalay N, Taflan Selçuk S, Ercidoğan Ö, et al: Meme Cerrahisi ve Aksiller Diseksiyon Uygulanan Meme Kanserli Hastalarda Üst Ekstremite Problemlerinin Sıklığı ve Yaşam Kalitesine Etkisi. Journal of Physical Medicine $\&$ Rehabilitation Sciences/Fiziksel Tup ve Rehabilitasyon Bilimleri Dergisi 14 (2011).

4 DiSipio, T, S Rye, B Newman, et al: Incidence of unilateral arm lymphoedema after breast cancer: A systematic review and meta-analysis. Lancet Oncol. 14 (2013), 500-515.

5. Cheville, AL: Current and future trends in lymphedema management: Implications for women's health. Phy. Med. Rehab. Clinics NA 18 (2007), 539-553.

6. Fu. MR, M Rosedale: Breast cancer survivors' experiences of lymphedema-related symptoms. J. Pain Symptom Mgmt. 38 (2009), 849-859.

7. Norman, SA, AR Localio, SL Potashnik, et al: Lymphedema in breast cancer survivors: Incidence, degree, time course, treatment, and symptoms. J. Clin. Oncol. 27 (2009), 390.

8. Fife, CE, W Farrow, AA Hebert, et al: Skin and wound care in lymphedema patients: A taxonomy, primer, and literature review. Adv. Skin Wound Care 30 (2017), 305-318.
9. Lee, TS, SL Kilbreath, KM Refshauge, et al: Prognosis of the upper limb following surgery and radiation for breast cancer. Breast Cancer Res. Treat. 110 (2008), 19-37.

10. Shaitelman, SF, KD Cromwell, JC Rasmussen, et al: Recent progress in cancer-related lymphedema treatment and prevention. Cancer 65 (2015), 55.

11. Mayrovitz, HN, N Sims, J Macdonald: Assessment of limb volume by manual and automated methods in patients with limb edema or lymphedema. Adv. Skin Wound Care 13 (2000), 272.

12. Ancukiewicz, M, CL Miller, MN Skolny, et al: Comparison of relative versus absolute arm size change as criteria for quantifying breast cancer-related lymphedema: The flaws in current studies and need for universal methodology. Breast Cancer Res. Treatment 135 (2012), 145-152.

13. Lymphatic filariasis: The disease and its control. Fifth report of the WHO Expert Committee on Filariasis. World Health Organization technical report series 821 (1992), 1-71.

14. The diagnosis and treatment of peripheral lymphedema: 2013 Consensus Document of the International Society of Lymphology. Lymphology 46 (2013), 1-11.

15. Szuba, A, R Achalu, SG Rockson: Decongestive lymphatic therapy for patients with breast carcinoma-associated lymphedema. Cancer 95 (2002), 2260-2267.

16. Rockson, SG, LT Miller, R Senie, et al: American Cancer Society Lymphedema Workshop. Workgroup III: Diagnosis and management of lymphedema. Cancer 83 (1998), 2882-2885.

17. The diagnosis and treatment of peripheral lymphedema: 2016 Consensus Document of the International Society of Lymphology. Lymphology 49 (2016), 170-184.

18. Ezzo, J, E Manheimer, ML McNeely, et al: Manual lymphatic drainage for lymphedema following breast cancer treatment. The Cochrane Library (2015).

19. Johansson, K, E Lie, C Ekdahl, et al: A randomized study comparing manual lymph drainage with sequential pneumatic compression for treatment of postoperative arm lymphedema. Lymphology 31 (1998), 56-64.

20. Szolnoky, G, B Lakatos, T Keskeny, et al: Intermittent pneumatic compression acts synergistically with manual lymphatic drainage in complex decongestive physiotherapy for breast cancer treatment-related lymphedema. Lymphology 42 (2009), 188.

21. Gurdal, SO, A Kostanoglu, I Cavdar, et al: Comparison of intermittent pneumatic compression with manual lymphatic drainage for 
treatment of breast cancer-related lymphedema. Lymph. Res. Biol. 10 (2012), 129-135.

22. Morgan, PA, CJ Moffat: International consensus on managing lymphoedema. Nursing Times 102 (2006), 42, 44.

23. Czerniec, S, L Ward, K Refshauge, et al: Assessment of breast cancer-related arm lymphedema-comparison of physical measurement methods and self-report. Cancer Invest. 28 (2010), 54-62.

24. Armer, JM, KV Ballman, L McCall, et al: Lymphedema symptoms and limb measurement changes in breast cancer survivors treated with neoadjuvant chemotherapy and axillary dissection: Results of American College of Surgeons Oncology Group (ACOSOG) Z1071 (Alliance) substudy. Support. Care Cancer (2018), 1-9.

25. Moseley, AL, CJ Carati, NB Piller NB: A systematic review of common conservative therapies for arm lymphoedema secondary to breast cancer treatment. Ann. Oncol. 18 (2007), 639-646.

26. Karadibak, D, T Yavuzsen, S Saydam: Prospective trial of intensive decongestive physiotherapy for upper extremity lymphedema. J. Surg. Oncol. 97 (2008), 572-577.

27. Zaleska, M, WL Olszewski, M Durlik: The effectiveness of intermittent pneumatic compression in long-term therapy of lymphedema of lower limbs. Lymph. Res. Biol. 12 (2014), 103-109.
28. Feldman, J, N Stout, A Wanchai, et al: Intermittent pneumatic compression therapy: A systematic review. Lymphology 45 (2012), 13.

29. Megens, AM, SR Harris, C Kim-Sing, et al: Measurement of upper extremity volume in women after axillary dissection for breast cancer. Arch. Phy. Med. Rehab. 82 (2001), 1639-1644.

30. Deltombe, T, J Jamart, S Recloux, et al: Reliability and limits of agreement of circuferential, water displacement, and optoelectronic volumetry in the measurement of upper limb lymphedema. Lymphology 40 (2007), 26.

\section{Dr. Canan Sanal Toprak \\ Marmara Üniversitesi \\ Eğitim Araştirma Hastanesi \\ Fiziksel Tip ve Rehabilitasyon Anabilim Dali}

Pendik 34899, Istanbul TURKEY

Tel: 90(533)1381032

Fax: 90(216)6254545

E-mail: canansanal@hotmail.com 